\title{
Effects of ingestion of a commercially available thermogenic dietary supplement on resting energy expenditure, mood state and cardiovascular measures
}

Jordan Outlaw ${ }^{1}$, Colin Wilborn ${ }^{*}$, Abbie Smith², Stacie Urbina', Sara Hayward ${ }^{1}$, Cliffa Foster ${ }^{1}$, Shawn Wells ${ }^{3}$, Rob Wildman ${ }^{3}$ and Lem Taylor ${ }^{1}$

\begin{abstract}
Background: Increasing metabolism is a primary focus of many commercially available dietary supplements marketed to support weight management. Caffeine (e.g. anhydrous and herbal) and green tea are key ingredients in such products, augmenting resting energy expenditure (REE) and improving reported mood states (alertness, fatigue, focus, etc.). The purpose of this study was to evaluate the effects of a thermogenic dietary supplement (DBX) on REE, respiratory exchange ratio (RER), reported measures of alertness, focus, energy, concentration, fatigue, and hunger, as well as the general safety of the product based on electrocardiogram (ECG) and hemodynamic responses in habitual caffeine consumers.

Methods: Six male and six female subjects (mean \pm SD; $22.50 \pm 3.22$ years; $76.94 \pm 14.78$ kg; $22.7 \pm 9.5 \%$ body fat), physically active ( $\geq 12$ months), and moderate habitual caffeine consumers ( $<200 \mathrm{mg} /$ day) received either two capsules of DBX containing $340 \mathrm{mg}$ of total caffeine plus green tea extract, yerba mate extract, carnitine tartrate and other active ingredients or a placebo (PLC) in a double-blinded, crossover design. Heart rate (HR), blood pressure (BP), REE, RER and perceived mood states were measured at baseline and then hourly for four hours after ingesting either treatment.

Results: Resting energy expenditure was significantly increased at all four time points and significant increases were determined for perceived alertness $(p=0.026)$ and focus $(p=0.05)$ at hour 1 and for energy at 1 and 2 hours after treatment for the DBX group ( $p=0.008$ and $p=0.017$, respectively). Additionally, perceived fatigue was decreased at the hour 1 assessment $(p=0.010)$. No significant differences were seen between DBX and placebo for hunger, anxiety, HR, BP, ECG patterns or RER.

Conclusions: The results of this investigation support that the proprietary blend of this thermogenic aid is capable of increasing REE for four hours post-ingestion while supporting increased focus, alertness, and energy as well as decreasing fatigue without promoting anxiety or causing significant changes in $\mathrm{HR}$, BP, or ECG measurements in habitual caffeine consumers.
\end{abstract}

Keywords: Caffeine, Thermogenic, Resting energy expenditure

\footnotetext{
* Correspondence: cwilborn@umhb.edu

${ }^{1}$ Human Performance Lab, Department of Exercise and Sport Science, University of Mary Hardin-Baylor, Human Performance Lab, Belton, TX 76513, USA

Full list of author information is available at the end of the article
} 


\section{Background}

Augmentations in overall metabolism and "fat burning" are two physiological expectations of consumers when purchasing a thermogenic dietary supplement. One of the primary reasons for taking a thermogenic aid is to support weight loss and body leaning [1]. Many of these products found on the market, and available to the general public, contain synthetic caffeine and herbal sources (e.g. guarana, yerbe mate), green tea extract, and other purported metabolic-supporting ingredients such as carnitine and capsaicin (red pepper extract). The most researched ingredient, caffeine, has been reported to have several potential ergogenic benefits including increased energy expenditure and weight loss, decreased body fat, as well as increased performance and a potential glycogen-sparing effect $[2,3]$. Green tea extract with a standardized level of catechins in combination with caffeine has been shown to significantly increase daily energy expenditure and fat oxidation over that of caffeine alone [4]. Rudelle and associates [5] investigated the effects of a thermogenic drink containing green tea catechins, as well as caffeine, on energy expenditure in lean individuals. The beverage increased resting energy expenditure (REE) by $4.6 \%$ and the authors suggested that this type of beverage could be beneficial for weight loss and management. The increase in energy expenditure reported by multiple researchers [6-9] positions caffeine and green tea-containing supplements as a beneficial tool to offset the reduction in energy expenditure associated with weight loss [10-12]. In addition to affecting metabolism and favoring fat as a fuel source, many studies have shown that caffeine has an impact on alertness, fatigue, and other mood states [13-15]. After ingesting $120 \mathrm{mg}$ of caffeine supplementation, greater alertness was reported for up to three hours by Mitchell and colleagues [13] and $40 \mathrm{mg}$ of caffeine combined with $97 \mathrm{mg}$ of L-theanine, the key caffeine analog in tea, showed improvements in perceived alertness and tiredness 20 and 70 minutes after ingestion in an investigation led by Giesbrecht and associates [14]. Caffeine levels of $250 \mathrm{mg}$ and $500 \mathrm{mg}$ also decreased reported tiredness and increased self-reported alertness when given to nine healthy subjects [15]. One important consideration in caffeine consumption studies is the control of habitual intake as individuals can become acclimated to caffeine, thus influencing their physiological responses to a specific dose.

Seeing these potential benefits for their consumers, supplement companies have created their own proprietary blends for weight management and body leaning supplements, as well as ergogenic aids containing caffeine. Many of these products claim to increase metabolism and "fat burning" either independently, or in conjunction with the caffeine contained in the supplement. Because of the popularity of weight management supplements, researchers have investigated different thermogenic products to determine their effectiveness. For instance, Hoffman and colleagues [16] determined that a commercially available product containing multiple trademarked ingredient mixtures demonstrated a trend for increased fat oxidation while also increasing heart rate (HR), systolic blood pressure (SBP) and reported levels of tension and confusion among the supplement group. Another study performed in 2009 [17] revealed that capsaicin, an active ingredient in the DBX proprietary blend, statistically increased energy expenditure and diastolic blood pressure (DBP) after ingestion but had no influence on fat utilization. A third investigation [18] revealed a significant effect for REE, as well as RER and SBP over three hours when regular coffee drinkers consumed a commercial product containing roughly $400 \mathrm{mg}$ total caffeine.

Based on these past studies, many thermogenic supplements are successful at increasing energy expenditure, but varying doses and combinations of ingredients may cause different cardiovascular and mood state side effects. Further product-specific research on thermogenic aids is needed to determine levels of effectiveness and safety for consumers. The purpose of this study was to evaluate the effects of a commercially available thermogenic dietary supplement on energy expenditure, reported measures of alertness, focus, energy, concentration, fatigue, and hunger, as well as the general tolerance and safety of the supplement based on ECG and hemodynamic responses when taken by healthy, active, young adults.

\section{Methods}

\section{Participants}

Six males and six females (mean \pm SD; age: $22.50 \pm 3.22$ years; weight: $76.94 \pm 14.78 \mathrm{~kg}$; body fat: $22.7 \pm 9.5 \%$ ) volunteered for the study conducted in the Human Performance Lab (HPL) at the University of Mary HardinBaylor in Belton, Texas. Participants were required to be apparently healthy, physically active (regularly participating in exercise for the previous 12 months), moderate caffeine users $(<200 \mathrm{mg} /$ day $)$, and were excluded from the study if they had any known metabolic disorders, were sensitive to caffeine, had a history of pulmonary disease, hypertension, liver or kidney disease, musculoskeletal or neuromuscular disease, neurological disease, autoimmune disease, or any cancers, peptic ulcers, or anemia. Taking certain medications, including those for heart, pulmonary, thyroid, anti-hyperlipidemic, hypoglycemic, anti-hypertensive, endocrinologic, psychotropic, neuromuscular, neurological, or androgenic conditions, as well as a family history of heart problems, high blood pressure, and/or stroke, and being pregnant or 
breastfeeding were also factors for exclusion. Trained lab assistants screened and examined participants as well as obtained a complete medical history to determine if each participant met the qualification standards. Participants reported the number of caffeinated beverages (coffee, tea, soft drink, energy drink, etc.), caffeine containing medications (NoDoz, Vivarin, etc.) and caffeine containing foods (candy, chocolate ice cream, etc.) as well as the serving size ( 8 oz., 5 oz., etc.) of each reported caffeinated product they consumed per week on average. Average caffeine consumption was determined to be $176.59 \pm 86.63 \mathrm{mg} /$ day. Volunteers were required to report any previous or current use of nutritional supplements, prescription and non-prescription medications. Participants were instructed to not change their nutritional supplement/medication intake over the course of the study and to report any changes to lab personnel.

\section{Instruments}

\section{Anthropometric measures}

Body composition was determined with the use of the Discovery QDR Dual-Energy X-ray Absorptiometry (DEXA) machine (Hologic, Inc., Bedford, MA). Participants were positioned in a supine position on the DEXA machine, in either workout shorts or hospital gown, and were asked to remain still during the entirety of the six minute scan. Percent body fat (\%Fat), fat free mass (FFM; grams), and fat mass (FM; grams) were collected from the DEXA report. Height was obtained from the SECA 242 measuring instrument (242, SECA, Hanover, MD) and recorded in both centimeters and inches. The TANITA Body Composition Analyzer (Model TBF-310, TANITA, Arlington Heights, IL) was utilized to measure weight in both kilograms and pounds.

\section{Resting energy expenditure}

REE was measured using a TrueOne ${ }^{\circledR} 2400$ metabolic measurement system (ParvoMedics, Sandy, UT). The metabolic cart was calibrated daily by trained laboratory assistants according to manufacturer guidelines. During testing, participants rested in a supine position with a blanket in a quiet, semi-dark room. A clear hood was placed over the participant's head and upper torso area. REE and respiratory exchange ratio (RER) data were collected from the last 20 minutes of the 25 minute test. For each breath, mean oxygen uptake $\left(\mathrm{VO}_{2}\right)$ and carbon dioxide output $\left(\mathrm{VCO}_{2}\right)$ were measured and then averaged over 15 second intervals. Flow rate was monitored by lab assistants during the course of the test and maintained at a rate of $1-1.2 \mathrm{~L} / \mathrm{min}$ of expired carbon dioxide. The test-retest correlations $(r)$ of this metabolic cart range from 0.814-0.956 [19].

\section{Mood state questionnaire}

A 5-point Likert scale questionnaire was used to measure perceived alertness, focus, energy, fatigue, concentration, and hunger. The participant placed a check mark in the specific box that correlated with their perceived mood level for all six categories. The numbers ranged from one (not feeling that particular mood) to five (highest level of mood).

\section{Hemodynamic assessments}

Electrocardiogram (ECG) leads were placed in standard clinical fashion to reveal 12 leads (I-III, $\mathrm{V}_{1}-\mathrm{V}_{6}$, aVR, aVL, aVF) throughout the testing session. Cardiac rhythm was monitored through a Quinton Eclipse Premier Electrocardiograph (Cardiac Science Corporation, Bothell, WA). Every five minutes, data were printed from the 12-lead ECG machine and RR interval, RP interval, QRS duration, and QT interval were recorded. If any abnormal readings/tracing were discovered, a note was added to the patient's file. Heart rate, recorded as beats per minute and SBP and DBP, recorded as $\mathrm{mmHg}$, were measured at baseline and hourly for four hours after consuming either treatment.

\section{Diet log}

Participants were instructed to maintain a diet log for four days prior to the first testing session, testing day one, as well as days between testing sessions. Lab personnel instructed participants to report foods eaten at breakfast, lunch, and dinner, as well as snacks. They were also instructed to record the method of preparation for each food and the quantity eaten (servings, cups, tablespoons, etc.). Trained HPL assistants input the data from the diet logs into the Food Processor Nutrition and Fitness Software (ESHA Research, Salem, OR) computer program, which was used to determine caloric intake based on reported information from participants.

\section{Supplement}

Our active supplement Dyma-Burn ${ }^{\circledR}$ Xtreme (Dymatize Enterprises, LLC, Dallas, TX) contains multiple ingredients combined to provide metabolic support including caffeine anhydrous, guarana, yerba mate green tea extract, L-carnitine L-tartrate $(200 \mathrm{mg})$, pathothenic acid (17 mg), chromium picolinate $(100 \mathrm{mcg})$ and proprietary blends containins , AssuriTea ${ }^{\mathrm{Tm}}$ Green Tea Extract (Kemin Nutritionals, Iowa City, IA), Salvia sclarea, raspberry ketones and Capsicum Annum extract, plus l-tyrosine, salix alba (white willow), zingiber officinale (ginger), focus vesiculosus (bladderwrack), panax ginseng, and Bioperine ${ }^{\circledR}$ (black pepper extract). The total caffeine and catechin content of the supplement was $340 \mathrm{mg}$ and $60 \mathrm{mg}$ respectively. 


\begin{tabular}{|c|c|c|c|c|c|c|c|}
\hline \multicolumn{8}{|c|}{ Testing day timeline } \\
\hline REE (ending time) & & & $\times$ & $\times$ & $\times$ & $\times$ & $\times$ \\
\hline ECG Begins & & $\times$ & & & & & \\
\hline Supplementation & & & $x$ & & & & \\
\hline $\mathrm{BP} / \mathrm{HR}$ & & & $x$ & $x$ & $\times$ & $\times$ & $x$ \\
\hline Mood State Ques. & & & $x$ & $x$ & $x$ & $x$ & $\times$ \\
\hline & $-45 \min$ & $-30 \mathrm{~min}$ & $0 \mathrm{~min}$ & $60 \mathrm{~min}$ & $120 \mathrm{~min}$ & $180 \mathrm{~min}$ & $240 \mathrm{~min}$ \\
\hline
\end{tabular}

REE testing began 25 minutes before the end of each hour and lasted for 25 minutes.

$\mathrm{HR}$ and BP were recorded at the end of each hour and participants completed a mood state questionnaire at this time point as well. ECG electrodes were placed before the baseline REE and data were printed every five minutes throughout the entirety of the testing session.

\section{Procedures}

Participants completed medical and exercise history surveys as well as signed an Informed Consent before beginning the study. Typical caffeine intake, over the counter drug usage, perceived fatigue, and appetite were reported along with daily caffeine consumption. All participants and paperwork were examined by qualified laboratory personnel. On the first day of the study, participants reported to the HPL at 8:00 am in a 12-hour fasted state. All testing sessions were held in the morning hours to reduce changes in REE due to performance of daily activities and stresses. This study was conducted in a double-blind, crossover manner with participants consuming either 2 capsules of a placebo (PLC) or 2 capsules of the active supplement (DBX). Before the initial treatment, DEXA was performed to assess body composition. Meanwhile, before either treatment, ECG electrodes were then positioned by HPL assistants and a baseline ECG was recorded. A 12 lead ECG printout was collected every five minutes throughout the testing period. A baseline metabolic test was conducted prior to supplementation and REE and RER data were recorded. After the initial REE session, each subject then consumed the randomly assigned treatment. Post supplementation, REE and RER data was collected from the last 20 minutes of the metabolic test at 60, 120, 180, and 240 minutes. At the end of testing day one, participants left the HPL and returned three days later to complete another testing session identical to the first with the exception of consuming whichever treatment was not consumed on test day one. A timeline for the testing day can be seen in Table 1.

\section{Data analysis}

All data was analyzed in SPSS using a mixed-factorial ANOVA [treatment (DBX vs PLC) x time (HR1 vs HR2 vs HR3 vs HR4)]. When a significant interaction was found, a lower order ANOVA with Bonferroni post-hoc corrections was used. A Kruskal-Wallis one-way analysis of variance was also used for all survey data. Significance was set at $p \leq 0.05$.

\section{Results}

\section{REE and RER}

A significant group $\mathrm{x}$ time interaction for change in resting energy expenditure $(p=0.001)$ was determined. From baseline to hour 4, REE increased by $147.33 \pm$ 83.52 for DBX and $32.17 \pm 86.72 \mathrm{kcal} /$ day for PLC $(p=0.003)$. Changes in $\mathrm{kcal} /$ day for all time points can be seen in Figure 1. A significant main effect for time was also reported $(p=0.001)$. Changes in REE from baseline for each time point are as follows: hour 1 (DBX: $123.4 \pm 78.2 \mathrm{kcal} /$ day vs. PLC: $-3.1 \pm 88.4 \mathrm{kcal} /$ day), hour 2 (DBX: $125.5 \pm 62.2 \mathrm{kcal} /$ day vs. PLC: $-20.3 \pm 72.6 \mathrm{kcal} /$ day), hour 3 (DBX: $142.4 \pm 101.16 \mathrm{kcal} /$ day vs. PLC: $9 \pm$ $114.77 \mathrm{kcal} /$ day), and hour 4 (DBX: $147.3 \pm 83.5 \mathrm{kcal} /$ day vs. PLC: $32.1 \pm 86.7 \mathrm{kcal} /$ day). Changes were significant $(\mathrm{p}<.05)$ between groups at all time points for REE. There were no significant time or interaction effects for RER at any time point.

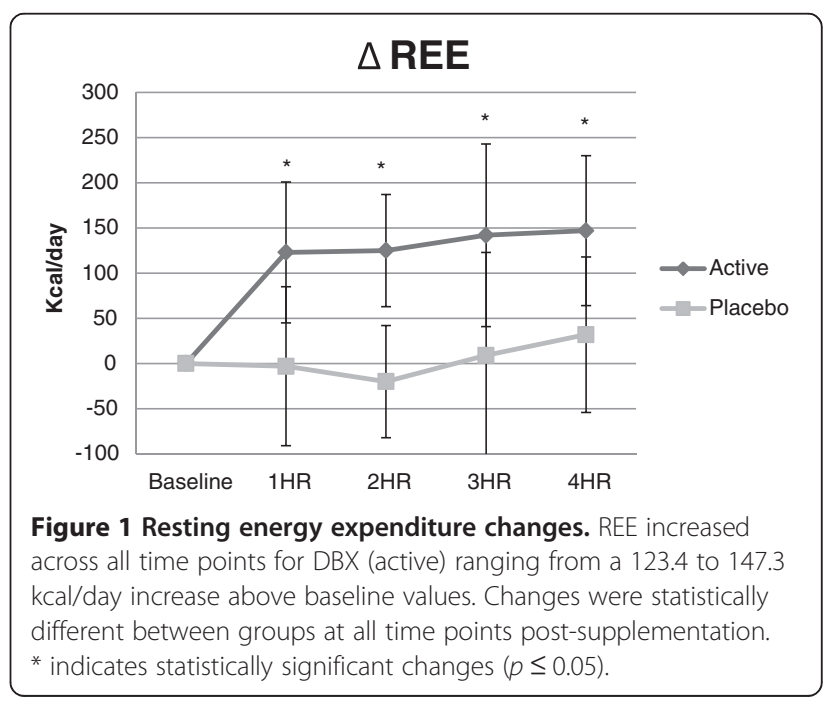




\section{Hemodynamic and ECG}

There were no significant $(p>0.05)$ group $\mathrm{x}$ time interactions and no main effects for time for SBP, DBP, or HR (Figure 2). There was no significant main effect for group $(p>0.05)$. At hour 1 , SBP increased by $12.4 \pm 11.8$ mmHG and $1.75 \pm 10.4 \mathrm{mmHG}$ for DBX and PLC, respectively from baseline values. From baseline to hour 2, SBP increased by $10.0 \pm 14.0 \mathrm{mmHg}(\mathrm{DBX})$ versus $0.0 \pm$ $7.9 \mathrm{mmHg}$ (PLC). Hour $3 \mathrm{SBP}$ deviated from baseline by $13.5 \pm 22.4 \mathrm{mmHg}$ for $\mathrm{DBX}$ and $-2.5 \pm 8.1 \mathrm{mmHg}$ for PLC. Hour 4 SBP increased above the baseline mean by $8.3 \pm 10.5 \mathrm{mmHg}(\mathrm{DBX})$ and $1.5 \pm 10.6 \mathrm{mmHg}$ (PLC). DBP changes from baseline to hour 1 were $4.8 \pm 7.4$ $\mathrm{mmHg}(\mathrm{DBX})$ versus $0.6 \pm 7.9 \mathrm{mmHg}$ (PLC). At hour 2, DBP changed from baseline by $-0.25 \pm 13.2$ (DBX) and $-1.0 \pm 7.2 \mathrm{mmHg}$ (PLC). Hour 3 values for DBP from

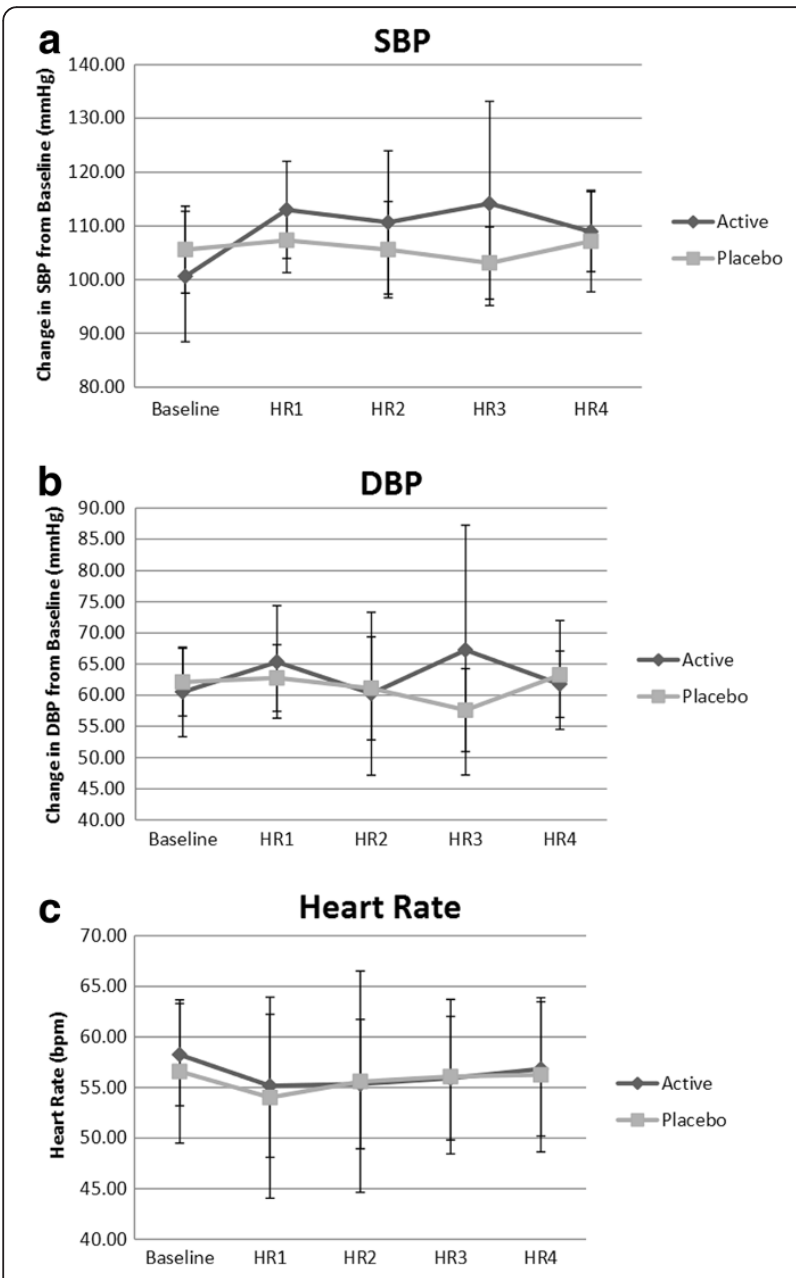

Figure 2 Hemodynamic measurement changes. a: Systolic Blood Pressure did not significantly differ from baseline values at HR1, 2, 3 or 4 for the active supplement group. $\mathbf{b}$ : Diastolic blood pressure did not significantly differ from baseline values at HR1, 2, 3 or 4 for the active supplement group. c: Heart rate, represented as beats per minute, was not significantly changed at any time point compared to baseline measurements for the supplement group. baseline for DBX were $6.7 \pm 20.9 \mathrm{mmHg}$ and for PLC were $-4.5 \pm 10.1 \mathrm{mmHg}$. The comparison against DBP baseline measurement for the DBX group at hour 3 was $1.25 \pm 6.8 \mathrm{mmHg}$ and $1.1 \pm 11.0 \mathrm{mmHg}$ for the PLC group. DBX versus PLC comparison to baseline in HR are as follows: hour $1(-3.0 \pm 6.2$ vs. $-2.5 \pm 5.5 \mathrm{bpm})$, hour $2(-2.9 \pm 6.5$ vs. $-1.0 \pm 10.0 \mathrm{bpm})$, hour $3(-2.3 \pm 5.6$ vs. $-0.5 \pm 8.7 \mathrm{bpm})$, and hour $4(-1.4 \pm 6.8$ vs. $-0.3 \pm 7.4$ bpm). (Data can be seen in Table 2 for SBP, DBP, and HR.) In addition to SBP, DBP, and HR, no significant differences in group or time were observed for the ECG intervals (RR, PR, and QT) or QRS duration. There were no observed changes in ECG rate and rhythm patterns.

\section{Subjective measures of mood state}

Significant within group increases $(p<0.05)$ were observed for both alertness $(p=0.026)$ and focus $(p=0.05)$ at hour 1 and energy at hour $1(p=0.008)$ and $2(p=$ 0.017 ) for DBX. Within group decreases in fatigue were observed for fatigue for the DBX group at the hour 1 time point, and no significant within group changes occurred for either hunger or concentration $(p>0.05)$. Mood state data can be seen in Figure 3.

\section{Discussion}

The results from this study indicate that this particular thermogenic aid is capable of significantly increasing

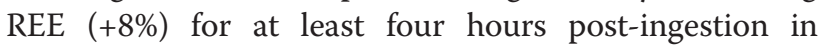
moderate-level habitual caffeine consumers. It is reasonable to contribute the increase in REE to the $340 \mathrm{mg}$ proprietary blend of caffeine anhydrous, guarana, yerba mate, and green tea extract found in the commercially available DBX. Caffeine is a known stimulant and increases energy expenditure and weight loss. In

Table 2 Hemodynamic Measures

\begin{tabular}{|c|c|c|c|c|c|c|}
\hline \multicolumn{7}{|c|}{ SBP, DBP, and HR Measurements Baseline to HR4 } \\
\hline & \multicolumn{2}{|c|}{$\underset{(\mathrm{mmHg})}{\mathrm{SBP} \text { mean } \pm S D}$} & \multicolumn{2}{|c|}{$\underset{(\mathrm{mmHg})}{\mathrm{DBP} \text { mean } \pm \mathrm{SD}}$} & \multicolumn{2}{|c|}{$\begin{array}{c}\mathrm{HR} \text { mean } \pm \mathrm{SD} \\
(\mathrm{bpm})\end{array}$} \\
\hline & DBX & PLC & DBX & PLC & DBX & PLC \\
\hline Baseline & $\begin{array}{c}100.58 \pm \\
12.12\end{array}$ & $\begin{array}{c}105.58 \pm \\
8.08\end{array}$ & $\begin{array}{c}60.50 \pm \\
7.20\end{array}$ & $\begin{array}{c}62.08 \pm \\
5.42\end{array}$ & $\begin{array}{c}58.25 \pm \\
5.07\end{array}$ & $\begin{array}{c}56.58 \pm \\
7.10\end{array}$ \\
\hline HR1 & $\begin{array}{c}113.0 \pm \\
9.04\end{array}$ & $\begin{array}{c}107.33 \pm \\
6.04\end{array}$ & $\begin{array}{c}65.33 \pm \\
9.03\end{array}$ & $\begin{array}{c}62.75 \pm \\
5.36\end{array}$ & $\begin{array}{l}55.17 \pm \\
7.09\end{array}$ & $\begin{array}{c}54.00 \pm \\
9.94\end{array}$ \\
\hline HR2 & $\begin{array}{c}110.67 \pm \\
13.36\end{array}$ & $\begin{array}{c}105.58 \pm \\
8.96\end{array}$ & $\begin{array}{c}60.25 \pm \\
13.06\end{array}$ & $\begin{array}{c}61.08 \pm \\
8.28\end{array}$ & $\begin{array}{c}55.33 \pm \\
6.41\end{array}$ & $\begin{array}{c}55.58 \pm \\
10.94\end{array}$ \\
\hline HR3 & $\begin{array}{c}114.17 \pm \\
19.00\end{array}$ & $\begin{array}{c}103.08 \pm \\
6.75\end{array}$ & $\begin{array}{c}67.25 \pm \\
20.01\end{array}$ & $\begin{array}{c}57.58 \pm \\
6.67\end{array}$ & $\begin{array}{c}55.92 \pm \\
6.11\end{array}$ & $\begin{array}{c}56.08 \pm \\
7.66\end{array}$ \\
\hline HR4 & $\begin{array}{c}108.92 \pm \\
7.44\end{array}$ & $\begin{array}{c}107.17 \pm \\
9.48\end{array}$ & $\begin{array}{c}61.75 \pm \\
5.33\end{array}$ & $\begin{array}{c}63.25 \pm \\
8.75\end{array}$ & $\begin{array}{c}56.83 \pm \\
6.64\end{array}$ & $\begin{array}{c}56.25 \pm \\
7.64\end{array}$ \\
\hline
\end{tabular}

$\mathrm{SBP}, \mathrm{DBP}$, and HR were recorded at baseline, HR1, HR2, HR3, and HR4. Measurements for SBP and DBP are reported as mean \pm SD and recorded in units of $\mathrm{mmHg}$. Changes in SBP and DBP were not significant at any time point for either group. Heart rate measurements were reported as mean $\pm S D$ and recorded in beats per minute. Changes in HR were not significant at any time point for either group. 


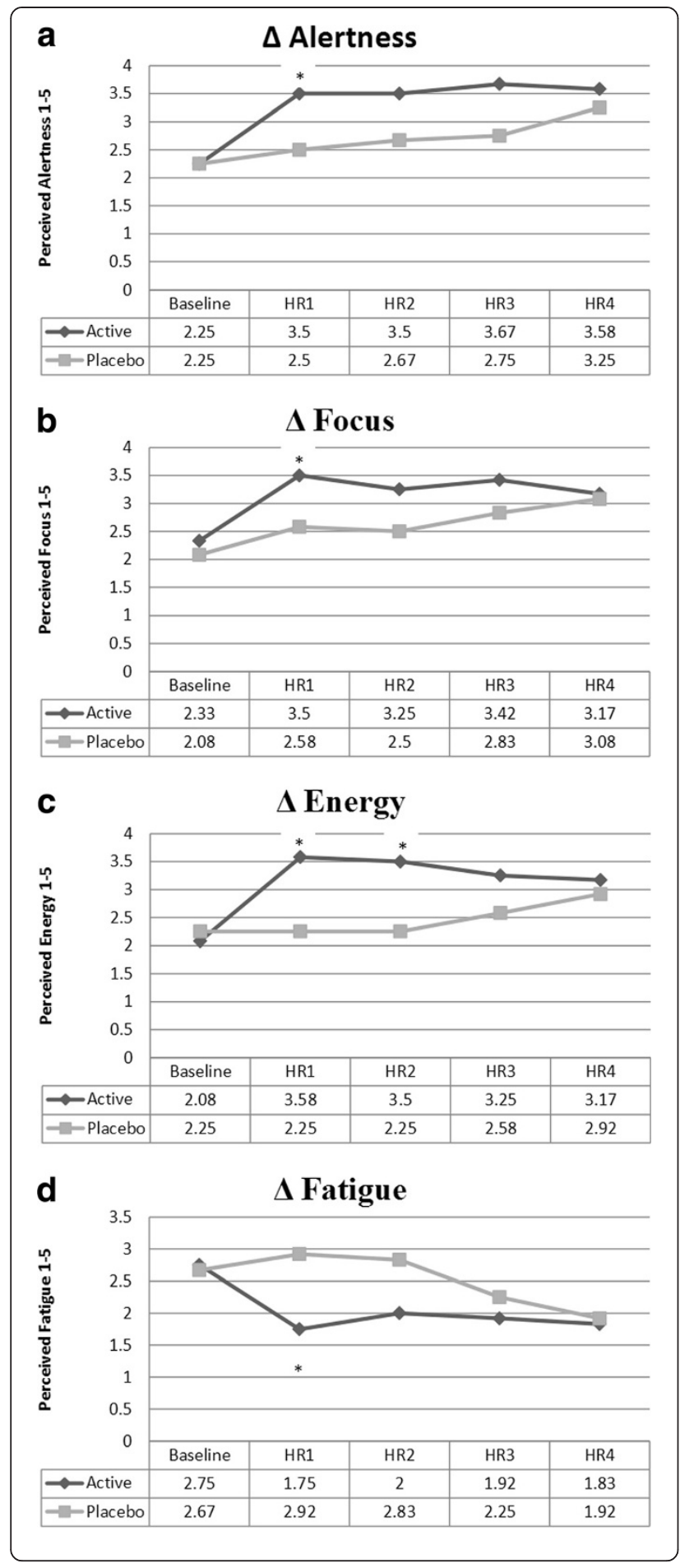

Figure $\mathbf{3}$ Changes in reported mood states. a: Alertness was reported on a 5-point Likert scale and rated one through five, five being the highest. Changes in alertness for the active supplement group were significant at HR1 only. ${ }^{*}$ indicates statistically significant changes $(p \leq 0.05)$. $\mathbf{b}$ : Focus was reported on a 5 -point Likert scale and rated one through five, five being the highest. A significant increase in focus was seen at HR1 for DBX. * indicates statistically significant changes $(p \leq 0.05)$. c: Energy was reported on a 5-point Likert scale and rated one through five, five being the highest. Changes in perceived energy were significant at both HR1 and HR2 for the supplement group. ${ }^{*}$ indicates statistically significant changes ( $p \leq 0.05)$. d: Fatigue was reported on a 5-point Likert scale and rated one through five, five being the highest. Decreases in fatigue were significant for the supplement group at HR1. ${ }^{*}$ indicates statistically significant changes $(p \leq 0.05)$.

combination with catechins, caffeine has been proven to decrease body fat percentage and waist circumference in overweight individuals [20]. Increased fat utilization as a fuel source is another benefit often associated with caffeine ingestion and supplementation. A 2011 metaanalysis [21] concluded that while caffeine ingestion increases energy expenditure, it appears to be unable to increase fat oxidation unless paired with catechins. Fat oxidation was significantly increased when $375 \mathrm{mg}$ of catechin was paired with $150 \mathrm{mg}$ of caffeine [22], 540 $\mathrm{mg}$ catechin with $300 \mathrm{mg}$ of caffeine [5], and when 662.5 $\mathrm{mg}$ of catechin was consumed with $270 \mathrm{mg}$ of caffeine [23]. The current study contradicts conclusions reported by Hursel and colleagues [13] as the Dyma-Burn ${ }^{\circledR}$ Xtreme supplement does contain a catechin-caffeine mixture but RER was not significantly changed over the four hour testing period $(p>0.05)$. This could possibly be explained by the lower level of catechin $(50 \mathrm{mg})$ used in this particular product. More so, differences may be attributed to the use of both men and women with varying resting RER levels. The results of this investigation suggest that while DBX can promote a rapid and sustained increase in REE, the increase is not due to enhanced fat oxidation. Research from 2001 [24] supports the RER data from the current investigation as Graham concludes that caffeine's role as a glycogen sparing aid is not fully supported by research.

The active supplement promoted increases in perceptions of alertness, focus, and energy, and also decreased fatigue without impacting perceived anxiety levels. These findings suggest that this product might have a favorable impact on the perceived quality of daily activities including exercise. Here again, caffeine is the most studied of the active ingredients and believed to be the main contributing factor to the positive changes in alertness, focus, energy, and fatigue. In a study by ZwyghuizenDoorenbos and colleagues [25], a dosage of $250 \mathrm{mg}$ of caffeine increased alertness in healthy young men. Those consuming the caffeine also performed better than those 
who received the placebo. With this in mind, this supplement may be beneficial for persons looking to burn more calories throughout the day and increase exercise performance. Furthermore, the experimental design of this study was based on an acute response and it is unclear at this time what the effects might have on chronic exercise and training adaptations when the product is taken for several weeks.

Of interest is the potential real world application of this study considering all of the participants were habitual caffeine consumers with a moderate daily intake of caffeine $(<200 \mathrm{mg} /$ day $)$ and were still responsive to the active supplement treatment. This regular intake of moderate amounts of caffeine may explain much of the lack of observed hemodynamic and ECG effects in this investigation. Tolerance to caffeine can develop within four days of consuming $150 \mathrm{mg} /$ day [26] and this builtup tolerance can negate or reduce the side effects often seen when a non-caffeine user ingests a caffeine-containing beverage/supplement including increases in SBP, DBP, and changes in HR [27]. In addition to a lack of negative physiological side effects, participants also did not report any negative mood states or other side-effects. When participants were given $280 \mathrm{mg}$ of caffeine in the form of coffee, Smits and associates [28] observed an increase in BP and a decrease in HR, while there were no significant changes among the control group (decaffeinated coffee). These changes in HR and BP were assumed to be linked to the caffeine content of the regular coffee. Considering the supplement used in the present study contained $340 \mathrm{mg}$ of total caffeine, habitual moderate caffeine usage seems to be the contributing factor to no significant changes in HR, BP, and ECG data, as well as the lack of reported side-effects.

\section{Conclusion}

In conclusion, when taken by moderate caffeine users that are physically active and healthy, the proprietary blend of this particular thermogenic supplement can increase REE and mood states related to alertness, focus, and energy without causing unsafe acute hemodynamic side-effects or increasing perceived anxiety levels. Future research should evaluate the chronic combined effects of DBX with exercise.

\section{Abbreviations}

REE: Resting energy expenditure; RER: Respiratory exchange ratio; ECG: Electrocardiogram; HR: Heart rate; BP: Blood pressure; SBP: Systolic blood pressure; DBP: Diastolic blood pressure; HPL: Human performance Lab; DEXA: Dual-Energy X-ray Absorptiometry; \%Fat: Percent body fat; FFM: Fatfree mass; $\mathrm{VO}_{2}$ : Mean oxygen uptake; $\mathrm{VCO}_{2}: \mathrm{CO}_{2}$ output.

\section{Competing interests}

Shawn Wells and Rob Wildman are employees of Dymatize Inc. Dymatize Inc. was the study funder. Neither contributor was involved in data collection or analysis. Their involvement was limited to manuscript preparation.

\section{Authors' contributions}

$\mathrm{JO}$ was the primary author and prepared the manuscript. CW was the primary investigator and designed the study. CW, AS, SW, and RW assisted with manuscript preparation. SU, SH, and LT conducted all testing and statistical analysis. CF provided administrative oversight. All authors read and approved the final manuscript.

\section{Acknowledgements}

We would like to thank all of our participants for volunteering for the study as well as all of the research assistants in the HPL that assisted with data collection. We would also like to thank Dymatize Nutrition for sponsoring this study.

\section{Author details}

'Human Performance Lab, Department of Exercise and Sport Science, University of Mary Hardin-Baylor, Human Performance Lab, Belton, TX 76513, USA. ${ }^{2}$ University of North Carolina at Chapel Hill, Chapel Hill, NC 27514, USA. ${ }^{3}$ Dymatize Nutrition \& Sport Performance Institute, $13537 \mathrm{~N}$. Stemmons Fwy, Dallas, TX 75234, USA.

Received: 11 February 2013 Accepted: 16 April 2013

Published: 30 April 2013

\section{References}

1. Dalbo VJ, Roberts MD, Stout JR, Kerksick CM: Acute effects of ingesting a commercial thermogenic drink on changes in energy expenditure and markers of lipolysis. Journal of the International Society of Sports Nutrition 2008, 5:6.

2. Kreider RB, Wilborn CD, Taylor L, Campbell B, Almada AL, Collins R, Cooke M, Earnest CP, Greenwood M, Kalman DS, Kerksick CM, Kleiner SM, Leutholtz B, Lopez H, Lowery LM, Mendel R, Smith A, Spano M, Wildman R, Willoughby DS, Ziegenfuss TN, Antonio J: ISSN exercise \& sport nutrition review: research \& recommendations. Journal of the International Society of Sports Nutrition 2010, 7:7

3. Roberts MD, Dalbo VJ, Hassell SE, Stout JR, Kerksick CM: Efficacy and safety of a popular thermogenic drink after 28 days of ingestion. Journal of the International Society of Sports Nutrition 2008, 5:9.

4. Dulloo A, Duret C, Rohrer D, Girardier L, Mensi N, Fathi M, Chantre P, Vandermander J: Efficacy of a green tea extract rich in catechin polyphenols and caffeine in increasing 24-h energy expenditure and fat oxidation in humans. Am J Clin Nutr 2000, 70:1040-1045.

5. Rudelle S, Ferruzzi MG, Cristiani I, Moulin J, Mace K, Acheson K, Tappy L: Effects of a thermogenic beverage on 24-hour energy metabolism in humans. Obesity 2007, 15:349-355.

6. Acheson KJ, Zahorska-Markiewicz B, Anantharaman K, Jequier E: Caffeine and coffee: their influence on metabolic rate and substrate utilization in normal weight and obese individuals. Am J Clin Nutr 1980, 33:989-997.

7. Dulloo AG, Geissler CA, Horton T, Collins A, Miller DS: Normal caffeine consumption: influence on thermogenesis and daily energy expenditure in lean and postobese human volunteers. Am J Clin Nutr 1989, 49:44-50.

8. Diepvens K, Westerterp KR, Westerterp-Plantenga MS: Obesity and thermogenesis related to the consumption of caffeine, ephedrine, capsaicin, and green tea. Am J Physiol 2007, 292:77-85.

9. Nagao T, Hase T, Tokimitsu I: A green tea extract high in catechins reduces body fat and cardiovascular risk in humans. Obesity 2007, 15:1473-1483

10. Westerterp-Plantenga MS: Green tea catechins, caffeine, and body-weight regulation. Physiol Behav 2010, 100:42-46.

11. Lockwood CM, Moon JR, Smith AE, Tobkin SE, Kendall KL, Graef JL, Cramer JT, Stout JR: Low-Calorie energy drink improves physiological response to exercise in previously sedentary men: a placebo-controlled efficacy and safety study. J Strength Cond Res 2010, 24:2227-2238.

12. Smith AE, Lockwood CM, Moon JR, Kendall KL, Fukuda DH, Tobkin SE, Cramer JT, Stout JR: Physiological effects of caffeine, epigallocatechin-3 -gallate, and exercise in overweight and obese women. Appl Physiol Nutr Metab 2010, 35:607-616.

13. Mitchell ES, Slettenaar M, Meer $\mathrm{V}$, Transler $\mathrm{C}$, Jans $\mathrm{L}$, Quadt F, Berry M: Differential contributions of theobromine and caffeine on mood psychomotor performance and blood pressure. Physiol Behav 2011, 104:816-822. 
14. Giesbrecht T, Rycroft JA, Rowson MJ, De Bruin EA: The combination of I-theanine and caffeine improves cognitive performance and increases subjective alertness. Nutr Neurosci 2010, 13:283-290.

15. Bruce M, Scott N, Lader M, Marks V: The psychopharmacological and electrophysiological effects of single doses of caffeine in healthy human subjects. Br J Clin Pharmacol 1986, 22:81-87.

16. Hoffman JR, Kang J, Ratamess NA, Rashti SL, Tranchina CP, Faigenbaum AD: Thermogenic effect of an acute ingestion of a weight loss supplement. Journal of the International Society of Sports Nutrition 2009, 6:1.

17. Ryan ED, Beck TW, Herda TJ, Smith AE, Walter AA, Stout JR, Cramer JT: Acute effects of a thermogenic nutritional supplement on energy expenditure and cardiovascular function at rest, during low-intensity exercise, and recovery from exercise. J Strength Cond Res 2009, 23:807-817.

18. Taylor LW, Wilborn CD, Harvey T, Wismann J, Willoughby DS: Acute effects of ingesting java fit energy extreme functional coffee on resting energy expenditure and hemodynamic responses in male and female coffee drinkers. Journal of the International Society of Sports Nutrition 2007, 4:10.

19. Wilborn C, Taylor L, Poole C, Bushey B, Williams L, Foster C, Campbell B: Effects of ingesting a commercial thermogenic product on hemodynamic function and energy expenditure at rest in males and females. Appl Physiol Nutr Metab 2009, 34:1073-1078.

20. Wang H, Wen Y, Du Y, Yan X, Guo H, Rycroft J, Boon N, Kovacs EMR, Mela $D J$ : Effects of catechin enriched green tea on body composition. Obesity 2010, 18:773-779.

21. Hursel R, Viechtbauer W, Dulloo AG, Tremblay A, Tappy L, Rumpler W, Westerterp-Plantenga MS: The effects of catechin rich teas and caffeine on energy expenditure and fat oxidation: a meta-analysis. Obes Rev 2011, 12:e573-e581.

22. Dulloo AG, Duret C, Rohrer D, Girardier L, Mensi N, Fathi M, Chantre P, Vandermander J: Efficacy of a green tea extract rich in catechin polyphenols and caffeine in increasing 24-h energy expenditure and fat oxidation in humans. Am J Clin Nutr 1999, 70:1040-1045.

23. Rumpler W, Seale J, Clevidence B, Judd J, Wiley E, Yamamoto S, Komatsu T, Sawaki T, Ishikura Y, Hosoda K: Oolong tea increases metabolic rate and fat oxidation in men. J Nutr 2001, 131:2848-2858.

24. Graham TE: Caffeine and exercise: metabolism, endurance and performance. Sports Med 2001, 31:785-807.

25. Zwyghuizen-Doorenbos A, Roehrs TA, Lipschutz L, Timms V, Roth T: Effects of caffeine on alertness. Psychopharmacology 1990, 100:36-39.

26. Robertson D, Wood D, Workman R, Woosley RL, Oates JA: Tolerance to the humoral and hemodynamic effects of caffeine in man. J Clin Invest 1981, 67:1111-1117.

27. Robertson D, Frolich JC, Carr RK, Watson JT, Hollifield JW, Shand DG, Oates JA: Effects of caffeine on plasma renin activity, catecholamines and blood pressure. N Engl J Med 1978, 298:181-186.

28. Smits P, Thien T, Van 'T Laar A: The cardiovascular effects of regular and decaffeinated coffee. Br J Clin Pharmacol 1985, 19:852-854.

doi:10.1186/1550-2783-10-25

Cite this article as: Outlaw et al.: Effects of ingestion of a commercially available thermogenic dietary supplement on resting energy expenditure, mood state and cardiovascular measures. Journal of the International Society of Sports Nutrition 2013 10:25.

\section{Submit your next manuscript to BioMed Central and take full advantage of:}

- Convenient online submission

- Thorough peer review

- No space constraints or color figure charges

- Immediate publication on acceptance

- Inclusion in PubMed, CAS, Scopus and Google Scholar

- Research which is freely available for redistribution

Submit your manuscript at www.biomedcentral.com/submit
Ciomed Central 